\title{
A JUSTIÇA RESTAURATIVA COMO POSSIBILIDADE DE JUDICIALIZAÇÃO DOS CASOS DE ESTUPRO CONTRA MULHERES?
}

\author{
Sandra Suely Moreira Lurine Guimarães*
}

\section{RESUMO}

O presente trabalho, por meio de um estudo bibliográfico, tem como objetivo discutir a possibilidade de adotar a Justiça Restaurativa nos casos de estupro contra mulheres. Isto porque o modelo tradicional de justiça criminal, declaradamente punitivista, tem como objetivo precípuo a adoção da punição sem considerar minimamente as necessidades das vítimas, que em regra é quase sempre vista como objeto probatório para fins de condenação ou absolvição do agressor. Considerando o número elevado de casos de estupro contra mulheres no Brasil, há a necessidade de uma reflexão sobre a inadequação do sistema criminal punitivista na judicialização dessa forma de violência.

Palavras-chave: Estupro. Justiça Restaurativa. Sistema Criminal. Revitimização.

\section{RESTORATIVE JUSTICE AS POSSIBILITY OF JUDICIALIZING CASES OF RAPE AGAINST WOMEN?}

\begin{abstract}
The present work, by means of a bibliographical research, has the goal of discussing a possibility of adopting Restorative Justice in the cases of rape against women. For the traditional model of criminal justice, confessedly punitivist, has as its main purpose the adoption of punishment without considering minimally the victim's needs, which is almost always seen as a probative object in order to condemn or absolve the aggressor. Considering the high number of rape cases in Brazil, there is the necessity for a reflection on the inadequacy of the punitivist criminal system in judicializing this form of violence
\end{abstract}

Key-words: Rape. Restorative Justice. Criminal System. Revictimization.

\section{INTRODUÇÃO}

O presente artigo objetiva discutir a possibilidade da adoção da justiça restaurativa nos crimes de estupro contra mulheres como alternativa ao modelo criminal punitivista. Isto porque teóricas como Andrade (2012) denunciam que o sistema criminal referido é ineficaz à abordagem da violência sexual contra mulheres, notadamente do estupro. Ressalta-se que essa

\footnotetext{
* Doutora em Ciências Sociais pela Universidade Federal do Pará. Mestre em Sociologia pela Universidade Federal do Pará. Bacharel em Filosofia Pela Universidade Federal do Pará. Bacharel em direito pelo Centro Universitário do Estado Pará. Professora da Faculdade FACI. Membro do Grupo de Pesquisa Filosofia Prática: Investigações em Política, Ética e Direito (CNPq.)
} 
prática é a manifestação mais atroz de violência contra a mulher, e que no Brasil, segundo os dados do Fórum Brasileiro de Segurança Pública de 2016, ocorre um estupro a cada 11 minutos. Com este artigo, pretende-se argumentar que a justiça restaurativa pode ser um modelo de justiça adequado ao tratamento desse tipo de violência.

Nesta perspectiva, adotou-se o método hipotético-dedutivo utilizando a pesquisa bibliográfica para alcançar o objetivo pretendido. Ressalta-se que as vítimas desse crime ficam com sequelas que não são sequer mitigadas pela mera aplicação da pena com a privação da liberdade do infrator. Por essa razão, aduziremos que o sistema criminal punitivista não tem se revelado adequado à abordagem judicial dos crimes de estupro quando a vítima é mulher, de modo que produz o fenômeno da revitimização.

Será feita uma explanação sobre o papel discriminatório da mulher vítima de crimes de estupro, quando esta adentra o sistema criminal. Assim, estudar as peculiaridades desse crime e os seus procedimentos legais, pelos quais a vítima deve percorrer, ajuda-nos a entender o sofrimento desnecessário vivido após o grande trauma que essa forma de violência ocasiona. Ademais, em meio a tantas desigualdades de gênero presentes na sociedade, as mulheres ainda são vistas como "provocadoras" ou "merecedoras" de tal sofrimento. Nesse sentido, surge a importância de uma prática não eventual para a solução desse conflito que possa priorizar a vítima no sentido de que ela não seja vista como mero objeto probatório no processo, mas que possa ter suas necessidades minimamente atendidas, no intuito de promover a reparação ou mesmo mitigar seu sofrimento.

Por fim, é indispensável discutir as razões pelas quais a justiça restaurativa ainda não ter obtido êxito no atual sistema punitivo brasileiro, principalmente em crimes de natureza sexual. Dessa forma, a problemática que norteia a proposta desse artigo é: de que modo a Justiça restaurativa pode contribuir com a judicialização nos casos de estupro? Nesta perspectiva, nosso objetivo consistiu em discutir como a justiça restaurativa pode ser uma via alternativa ao modelo de justiça criminal punitivista, nos casos de estupro contra mulheres, por se revelar mais adequado à abordagem dessa forma de violência, na medida que seu cerne é vítima e a reparação do dano.

\section{O PAPEL DISCRIMINATÓRIO DA MULHER NOS CRIMES DE ESTUPRO}


O estupro é certamente uma das manifestações de violência mais antigas da história da humanidade. Já foi inclusive considerado crime contra o patrimônio, considerando que a mulher era propriedade do pai e depois do marido. Por consequência desse raciocínio jurídico, esse delito não era punido em razão da violência que causava, mas propriamente por constituir uma violação ao patrimônio de outro homem. Assim, percebe-se que sequer havia a visibilidade da mulher como vítima, mas a preocupação com a propriedade.

De acordo com Vigarello (1998), somente a partir do século XVI o estupro começa a ser visto como uma forma de agressão, mas não contra a mulher e sim contra a honra de sua família. Desta feita, caso a mulher fosse virgem e de família abastada, havia uma reprovabilidade maior, do mesmo modo que mais intenso esforço em punir o agressor considerando a necessidade de restaurar a honra da família

No ordenamento jurídico brasileiro, o crime de estupro encontra-se no rol de crimes contra a Dignidade Sexual. No entanto, pelo modus operandi e pelas consequências de tal prática delitiva, é considerado, também, uma afronta à própria dignidade humana, tipificado no art. 213 do Código Penal Brasileiro. O bem jurídico protegido é a dignidade sexual do ofendido, ou seja, o seu direito de usar livremente da sua sexualidade. Ressalta-se, nesse aspecto, a autonomia da vontade, no que tange à liberdade sexual, e por consequência, a integridade do corpo, que inclusive é tida como condição para a soberania do sujeito.

Esse direito de manifestar livremente a sexualidade não pode ser negado sequer no caso da vítima ser prostituta, razão pela qual é reservada à profissional do sexo a faculdade de aceitar ou não ter relações sexuais. Essa ressalva, ainda que pareça desnecessária, justifica-se na medida em que o judiciário brasileiro tende, em alguns julgados, a negar o bem jurídico dignidade sexual, no caso de estupro, quando a vítima é prostituta.

Parece inconteste que o estupro é a manifestação mais atroz da dominação masculina sobre a mulher, isso porque é um ato violento no qual o corpo da vítima é usado para a satisfação do impulso sexual mais primitivo. No estupro, há eliminação da soberania sobre o corpo, o que já foi considerado como elemento fundamental para o acesso à cidadania. Além disso, o sofrimento da vítima é ignorado, e sua autonomia e dignidade são profundamente negadas, acarretando assim sua verdadeira objetificação. Trata-se de um fenômeno social, em virtude de não ser pontual e ocorrer segundo padrões amplamente presentes e, de certo modo, aceitos na sociedade. 
Alguns elementos presentes no estupro, tais como a ocorrência majoritariamente contra as mulheres e a depreciação da vítima por meio do questionamento de sua conduta pessoal e moral, dentre outros, possibilitam defender que se trata de um crime de gênero ${ }^{1}$, uma vez que é praticado por homens contra mulheres e revela uma concepção masculina de dominação social, corolário do patriarcado. Assim entendido, o estupro é uma forma de manifestação do poder masculino pautado na submissão feminina que resulta no domínio do corpo da mulher.

Desta feita, institui-se e consolida-se a cultura do estupro $^{2}$, traduzida pela reificação da mulher, de sorte que a violência sexual corre o sério risco de ser naturalizada, dada a sua incidência e a tolerância social face a mesma. Diante dessa realidade, é bastante razoável, conquanto lamentável, que um dos grandes receios de uma mulher, malgrado a violência multifacetária, seja exatamente o de ser vítima do estupro, receio esse vivenciado de forma reiterada e exclusivamente por mulheres.

O estupro contra mulheres revela a condição de vulnerabilidade da mulher face à sua condição desigual em relação ao poder masculino. Ressalta-se que a vulnerabilidade não é um atributo do sujeito, mas uma situação na qual ele é colocado. Assim, a vulnerabilidade é traduzida por uma fragilidade que, por sua vez, remete à desigualdade em relação a outros, representando menos poder nas relações, portanto, uma relação assimétrica

A prática do estupro revela uma forma de vulnerabilidade que decorre do gênero, tendo em vista o tratamento da mulher ao longo da história. Esse teve os mais diversos fundamentos, cujo elemento central era visão de uma suposta inferioridade da mulher em relação ao homem.

\footnotetext{
${ }^{1}$ Gênero é um conceito das Ciências sociais que começou a ser utilizado a partir da década de 1960, para se contrapor à ideia de que a desigualdade entre homens e mulheres era decorrente de suas diferenças biológicas, portanto, naturais. Os elevados números de violência sexual contra é um demonstrativo de que a violência sexual, especialmente o estupro, é um crime de gênero. No que concerne ao fato de ser um crime de gênero, o estudo realizado pelo do IPEA em 2014 revelou que 96,66\% dos agressores são do sexo masculino. Todavia, é importante destacar que a violência de gênero, de acordo com Saffioti (2015, p.47), engloba tanto a violência de homens contra mulheres quanto a de mulheres contra homens, uma vez que, segundo a autora o conceito de gênero é aberto. No entanto, no que concerne ao estupro, conforme já exposto, trata-se faticamente de uma violência de homens contra mulheres

2 De acordo com Campos et al (2017 p.983), a noção de cultura do estupro, é produto da literatura feminista acadêmica norte-americana. Para algumas teóricas norte-americanas, existe uma cultura que apoia o estupro, com base na forma como essa cultura define a sexualidade masculina como naturalmente agressiva e a feminina como passiva. Demais disso, essa mesma cultura impõe papeis sociais às mulheres que devem se comportar de forma recatada, delicada e de não assertividade. Campos acrescenta ainda que na lógica da cultura do estupro, as mulheres são ensinadas a se comportarem de forma adequada o que inclui não andar sozinha, não usar roupas provocativas, como medidas para evitarem o estupro. Nesta perspectiva, há uma tendência da sociedade naturalizar o estupro, quando ocorre em circunstâncias que, supostamente, a vítima concorreu para sua vitimização. Sobre a existência de uma cultura do estupro, no Brasil, é mister destacar os dados fornecidos pelo Fórum Brasileiro de Segurança Pública de 2016, que atestam a ocorrência de 125 estupros por dia, sendo necessário considerar o fenômeno da subnotificação. Isto nos leva à conclusão que a ocorrência dessa violência seja muito maior, tendo em vista o número de casos não notificados
} 
Neste aspecto, destaca-se o recurso a fatores biológicos para "explicar" a condição de inferioridade biológica da mulher. Ademais, é importante ressaltar que nem sempre as mulheres tiveram voz, para publicizar as violências das quais eram vítimas. Perrot (2017)considera que o silêncio ao qual as mulheres estiveram submetidas, esteve relacionado historicamente à invisibilidade que lhes foi imposta

No que se refere à visão biológica que tentava justificar a inferioridade da mulher, face ao homem, é somente com sua relativização que emerge a concepção de que, no que concerne às mulheres, trata-se de um grupo social com tarefas específicas, sem visibilidade e acesso a direitos. Nesta perspectiva, as diferenças entre o feminino e o masculino deixam de serem vistas como inferioridade do primeiro face ao último e passam a ser entendidas como resultados de construções socioculturais.

No ato violento do estupro, a subjetividade da mulher é completamente negada, assim como sua autonomia e dignidade são totalmente violadas, o que acarreta seu processo de vitimização. Por essa razão, interessa-nos analisar se, na condição de vítima em meio ao processo criminal, a mulher é, pela segunda vez, colocada na condição de objeto probatório, o que resulta na sua revitimização, tal como elucida Câmara ao afirmar que:

O fenômeno da estigmatização ou revitimização da vítima ocorre, preferencialmente, no espaço processual penal, considerado como a mais angustiante das cerimônias degradantes (...) e implica em uma intensificação e ampliação dos danos (materiais ou imateriais) que a vítima sofrera com o delito. Demais disso, já no ambiente policial, é possível constatar na qualidade de first line enforcer os agentes policiais "não brincam em serviço" quando se trata de conferir rótulos degradantes a determinadas vítima (CÂMARA, 2008, p. 84, Destaques no original).

Na perspectiva do direito penal, o estupro é um crime doloso, ou seja, é necessário a vontade de constranger alguém, mediante violência ou grave ameaça, a ter conjunção carnal ou a praticar ou permitir que com ele se pratique outro ato libidinoso (CUNHA, 2016). Com a reforma no Código Penal, trazida pelo advento da Lei 12.015/2009, qualquer pessoa pode praticar ou sofrer a infração penal. Torna-se necessário explicar que o autor do crime de estupro não necessariamente será aquele homem dotado de alguma patologia sexual ou social, como fica claro na seguinte passagem:

O crime de estupro ocorre com qualquer mulher e pode ser cometido por qualquer homem, sem se especificar idade, cor, etnia, raça, condição econômica 
ou nível cultural. Não existe um perfil específico de estuprador e muito menos de vítimas, podendo os agressores serem quaisquer pessoas, e até mesmo aqueles em que menos se espera, como marido, irmão, tio, colega de trabalho, patrão, amigo, etc., abrangendo todas as classes sociais, e sem nenhuma motivação especial para o feito. (SANTOS, 2014, p.45)

Em crimes de tal natureza, a palavra da vítima é de suma importância para o desenvolver de um processo criminal, haja vista que os crimes sexuais, como o estupro, nem sempre têm comprovação simples, por ocorrerem de forma clandestina, em regra, na ausência de testemunhas. Aliado a isso, muitas vezes as vítimas sentem medo, humilhação e vergonha de comparecerem à delegacia, para denunciar o fato. Com isso, passa-se muito tempo, prejudicando o resultado de exames realizados no Instituto Médico Legal. Nesse sentido, a palavra da vítima deve ser considerada a principal prova para a possível condenação do agressor.

A trajetória a ser percorrida pela vítima após a difícil decisão de denunciar o estupro é lenta, árdua e sinuosa, e tem início com a fase considerada pré-processual, por meio do inquérito policial $^{3}$. Destaca-se que nesse momento a vítima é instada a fazer o relato do ato violento em um ambiente completamente destituído dos meios adequados para seu acolhimento. Isso fica menos constrangedor quando é realizado em uma Delegacia de mulheres. Nesse primeiro contato com o sistema criminal, a discriminação já revela sua face, de modo que tem início a suspeita que deverá acompanhar a vítima nas demais etapas do curso do processo. É o que defende Câmara na seguinte passagem:

Na práxis constroem-se estereótipos que se adscrevem às vítimas de certos tipos de crime e, uma vez que a vítima concreta não preencha certas características peculiares ao clichê ou arquétipo-padrão, em lugar de ser apoiada, ouvida e de receber solidariedade e atenção(...) não apenas não é devidamente acolhida, como principalmente a vítima feminina em delitos relacionados com a autodeterminação sexual(...) não raro, é tratada como suspeita ou provocadora (CÂMARA, 2008, p. 84, Destaque no original).

\footnotetext{
${ }^{3}$ Sobre o inquérito policial, Oliveira (2011) esclarece que se trata da atividade específica da polícia denominada judiciária que, no âmbito da Justiça Estadual, concerne à Polícia Civil e, na Justiça Federal, à Polícia Federal. O inquérito tem por objetivo realizar a apuração das infrações penais e de sua autoria, tal como resta claro no art. $4^{\circ}$, do Código de Processo Penal. Essa fase pré-processual tem sua razão maior no convencimento daquele que é responsável pela acusação. Destaca Oliveira que, na fase do inquérito, o juiz, órgão acusador, sequer deveria ter contato com a investigação. A participação do juiz, nesse momento, só se justificaria quando houvesse lesão, risco ou ameaça de lesão às garantias fundamentais. De acordo com a legislação vigente, o prazo para que o inquérito seja concluído e enviado ao Ministério Público é de 10 (dez) dias se o acusado já estiver preso, em virtude de flagrante, e de 30 (trinta) dias caso o acusado esteja em liberdade.
} 
No decorrer do processo a mulher vítima deve expor reiteradas vezes sua intimidade, sem que o magistrado considere o aspecto traumático de se rememorar o ato violento, o que não deve ocorrer sem uma certa carga de sofrimento. Desta feita, ela deve prestar depoimento da forma mais inequívoca possível de modo a não deixar qualquer traço de incoerência ou contradição. Ressalta-se que, no momento da oitiva da mulher que sofreu a violência, seu relato é avaliado tão somente como um elemento probatório, sem que se considere que relatar a violência é rememorar a dor que ela carrega. Em razão do exposto, cabe questionar se o sistema criminal, seguindo sua lógica de funcionamento, pode ser um mecanismo eficaz de reparação às vítimas de estupro

\section{O SISTEMA CRIMINAL É EFICAZ NA PROTEÇÃO DAS VÍTIMAS DE ESTUPRO?}

A criminologia crítica, recente campo de saber voltado ao estudo da criminalidade, tem como um de seus principais méritos a revelação de que o sistema criminal é calcado em uma contradição inescapável entre a igualdade formal dos sujeitos de direito e a desigualdade substancial dos indivíduos (CAMPOS, 1999). Esta última é traduzida pela seletividade concernente à classe e raça, que realiza a seleção dos sujeitos que podem ou não ser considerados delinquentes. Todavia, malgrado a criminologia crítica ter realizado a denúncia da seletividade do sistema criminal no que tange à seletividade de classe e raça, não teve o alcance ou mesmo a intenção de ampliar a seletividade para abarcar a categoria de gênero e, com isso, expor o tratamento que esse sistema dispensa às mulheres, sejam como vítimas ou autoras de crimes.

As demandas judiciais quase sempre são acompanhadas das dores dos sujeitos que ingressam no judiciário. Dessa forma, no campo do sistema criminal chegam as maiores manifestações de sofrimento no que diz respeito à violência sexual contra a mulher, sobremaneira o estupro. O direito penal, como poder punitivo, é marcadamente seletivo ao escolher quem é o inimigo do Estado, ou seja, ser violador da norma penal. Todavia, essa seletividade recai sobre a vítima quando uma mulher sofre a violência do estupro. Isto porque nos julgamentos do estupro é comum que o sistema criminal opere um deslocamento do foco do fato criminoso para a moral sexual e o comportamento pregresso da vítima

O modelo punitivista, tradução do direito penal moderno, consiste em um padrão de soluções de conflitos cujo traço marcante é a adoção da pena como única resposta à prática delituosa. Isso fica claro quando se constata que a própria denominação do campo jurídico que se 
ocupa do crime, é denominada de direito penal. Diante disso, resta claro que a função precípua do sistema criminal na aplicação do direito penal é a aplicação da pena a qualquer prática que possa ser tipificada como crime. Os questionamentos que ora fazemos é: o modelo criminal tradicional é adequado à abordagem de qualquer tipo de crime? Nos casos de violência contra a mulher, especialmente nos casos de estupro, o direito penal é uma estratégia eficaz no combate a essa forma de violência?

A pertinência desses questionamentos decorre da necessidade, ainda que com limites precisos, de uma discussão sobre a contribuição da criminologia feminista como reveladora dos limites e problemas do discurso penal na garantia dos Direitos Humanos, especialmente no combate à violência sexual contra a mulher

A este respeito, Campos (2002) defende que a grande contribuição da criminologia feminista foi precisamente em relação à tese da seletividade penal apontada pela criminologia crítica, ao constatar que a referida seletividade não contemplava a desigualdade de gênero. Assim, segundo essa autora, a criminologia crítica desconsiderou a gênese da opressão exercida sobre as mulheres, reduzindo sua análise à classe e raça sem englobar o gênero, de modo que:

As criminólogas feministas sustentaram que a opressão da mulher não pode ser
reduzida á opressão de classe, pois ela é anterior e distinta, produto da estrutura
patriarcal da sociedade(...). Determinados mecanismos como o medo, a
violência, a sexualidade, a ideologia dirigida especialmente às mulheres lhes
atribuem um determinado papel (CAMPOS, 2002, p. 140-141)

Desta feita, é somente sob a influência do movimento feminista que o sistema criminal será criticado a partir da categoria de gênero, de modo a expor as inadequações desse sistema no concernente às mulheres vítimas de violência, especialmente a sexual. Assim, a criminologia feminista inovou ao denunciar que a seletividade do sistema criminal envolve também o marcador gênero, que encerra a complexa articulação entre patriarcado e direito penal. Um dos pontos de convergência entre direito penal e patriarcado é a pretensa defesa da sociedade, de valores sociais, e da manutenção da ordem. Entretanto, o traço invisível desse entrelaçamento é, na verdade, o controle dos corpos e das vontades.

A discriminação entre o masculino e o feminino estabelece papeis rígidos e fixos a cada um deles. Desse modo, o gênero é o referencial na atribuição de papeis a mulheres e homens, assim ocorrendo a legitimação de determinadas práticas sociais. Ao homem cabe o espaço público para exercer seu protagonismo, por ser considerado produtivo, especialmente no mundo 
do trabalho; à mulher, resta a dimensão privada, doméstica, o âmbito familiar. Esse espaço que lhe é atribuído serve também de controle sobre sua sexualidade e assim normatiza seu comportamento. Isso faz com que nos casos de estupro haja um julgamento prévio sobre o comportamento da mulher, de sorte a decidir quem é a "vítima genuína" que merece a proteção estatal, e aquela que, segundo o sistema de justiça, não sofreu violação do bem jurídico, dignidade sexual, como ocorre no casos das prostitutas, tal como fica claro no seguinte julgado:

\section{Ementa}

ESTUPRO. VERSÃO DA VÍTIMA PROSTITUTA. VERSÃO INVEROSSIMEL. FALTA DE PROVAS. RECURSO IMPROVIDO.

A sentença decidiu com acerto, ante a falta de prova da existência do crime. (...) em se tratando de uma prostituta, sua estória há de ser examinada com reservas (Grifo nosso) ${ }^{4}$.

A decisão em análise é particularmente ilustrativa daquilo que estamos argumentando, ou seja, que o sistema punitivista se revela inadequado à abordagem dos casos de estupro por reproduzir a visão do senso comum, de modo a condenar as mulheres vítimas quando elas não se encaixam nos papeis sociais que lhes foram atribuídos. Nessa situação concreta, fica evidente que o julgamento incide no comportamento sexual e na vida pregressa da vítima, de modo que o relato do estupro, por vezes único elemento probatório, recai no que Andrade (2012) considera uma hermenêutica da suspeita. O julgado revela também que, malgrado a mudança legislativa no crime de estupro, que retirou a expressão mulher honesta do tipo penal, permanece na mentalidade do julgador a lógica da honestidade, que divide as mulheres entre as que foram vítimas do estupro e aquelas que provocaram o ato.

O sistema criminal, ao julgar o estupro pelo viés da conduta social e moral feminina, acaba por afirmar e reafirmar socialmente que uma mulher de boa reputação e "cuidadosa" terá menos chances de ser vítima desse ato. Pensar assim significa não refletir, porque, em culturas nas quais mulheres usam burcas e têm pouco trânsito no espaço público, observa-se a ocorrências de crimes da mesma natureza. Esse discurso, que imputa às mulheres a responsabilidade por sua própria dor, acarreta uma tolerância quanto a esse delito, legitimando assim a cultura do estupro.

\footnotetext{
${ }^{4}$ Trecho retirado da decisão dos desembargadores da Primeira Câmara Criminal do Tribunal de Justiça do Paraná. Processo: ACR 48582 Apelação Crime - 0004858-2. Relator: Eli R. de Souza, Data de Julgamento: 12/08/1993
} 
Destarte, é imprescindível pensar alternativa de judicialização dos casos de estupro, de modo que seja possível oferecer proteção e tratamento digno às mulheres vítimas. Por essa razão pertine pensar a Justiça Restaurativa como essa possibilidade. Nesse novo modelo, é de extrema importância a valorização da vítima com o intuito da reparação, mas que não descura da preocupação com o autor do delito, assim como a comunidade.

O que se constata é que o modelo criminal voltado estritamente à punição e reiterador da discriminação de gênero apenas reproduz os preconceitos que alimentam o senso comum e, tal como essa estrutura, também imputa à mulher a responsabilidade da violência da qual foi alvo. Assim, reiteramos a necessidade da adoção de outro modelo de justiça, tal como foi exposto, mas, acima de tudo, uma mudança de mentalidade daqueles que, conforme Bourdieu, tem a autoridade de dizer o direito. Por essa razão é imprescindível pensar em um modelo alternativo de justiça que ultrapasse o limite da simples punição, cujo cerne seja atender os interesses da vítima no que diz respeito à reparação, todavia, sem descurar do agressor, tal como preconiza a Justiça Restaurativa.

\section{A POSSIBILIDADE DA ADOÇÃo DA JUSTIÇA RESTAURATIVA E AS NECESSIDADES DAS VÍTIMAS}

Antes de discutir a possibilidade da adoção da Justiça Restaurativa nos casos de estupro contra mulheres, é de extrema importância trazer uma breve exposição dessa forma alternativa de justiça. Isto posto, a Justiça Restaurativa pode ser conhecida como uma técnica de solução de conflitos, caracterizados como crimes, que prima pela sensibilidade na escuta e destaque trazidos às vítimas, tal como defende Zehr (2012, p. 24, grifo nosso):

A Justiça Restaurativa se preocupa em especial com as necessidades das
vítimas de atos ilícitos, aquelas necessidades que não estão sendo
adequadamente atendidas pelo sistema de justiça criminal. Não raro as vítimas
se sentem ignoradas, negligenciadas ou até agredidas pelo processo penal.
Isto acontece em parte devido à definição jurídica do crime, que não inclui a
vítima. O crime é definido como ato cometido contra o Estado, e por isso o
Estado toma o lugar da vítima no processo.

Destarte, a vítima passa a ter papel de maior evidência e voz ativa. Além disso, tem participação e controle dos procedimentos utilizados, recebendo: assistência, afeto, restituição de perdas materiais e reparação. Assim, com a justiça restaurativa suprem-se as necessidades 
individuais e coletivas da vítima e da comunidade, pois, de acordo com Bianchini (2012), em razão da vítima ter um papel essencial, essa tem a oportunidade de expressar suas angústias e sentimentos geralmente negligenciados no sistema tradicional, assim como oportuniza ao criminoso a assunção de sua culpa e responsabilidade.

Demais disso, a Justiça Restaurativa tem como escopo a redução do sistema criminal, a fim de que este seja o último recurso, e assim mitigar seus efeitos, seja para os sujeitos envolvidos, autor e vítima, seja para o Estado. Em acréscimo, a Justiça Restaurativa possibilita a democratização dos conflitos penais, na medida em que há o verdadeiro protagonismo dos envolvidos na gestão do drama penal. A aplicação da Justiça Restaurativa se dá por meio de diversas formas de diálogo entre os envolvidos, utilizando-se de técnicas presentes na mediação, conciliação ou círculos restaurativos, buscando a retomada do equilíbrio abalado pelo crime.

Deve-se ressaltar que a participação da vítima, bem como dos outros integrantes no procedimento da Justiça restaurativa, deve ser de forma voluntária. Caso contrário, poderiam ser revividas agressões e traumas decorrentes da prática delitiva, resultando em maiores prejuízos à vítima. Quanto a esta última, esse modelo alternativo, de acordo com Achutti (2016, p. 80) se mostra como "um sistema de atenção às vítimas(...) que há interesse público com a situação de vitimização e em buscar minimizar as consequências da ação sofrida”.

A fala honesta e veraz da vítima não tem por objetivo servir de elemento probatório para fins de condenação do ofensor. Como se trata de um modelo cujo enfoque central é a vítima, a valorização do seu relato representa a oportunidade de expor seus sentimentos, seu sofrimento. A esse respeito, Zehr (2012, p. 25) considera que:

Um elemento importante no processo de recuperação ou superação da vivência do crime é a oportunidade de narrar o acontecido (...) é importante para a vítima contar a história àqueles que causaram o dano, fazendo-os entender os impactos de suas ações.

Em relação à fala da vítima, em regra único elemento probatório nos casos de estupro, a Justiça Restaurativa não tem como objetivo utilizá-la como prova contra o agressor, mas sim a oportunidade da vítima em expor seu sofrimento. Nesse sentido, o diálogo não assume unicamente o contorno de depoimento ou testemunho, que servirá para fins de condenação ou absolvição do agressor, como é a regra no modelo convencional.

Nossa opção por discutir o modelo restaurativo de justiça em um trabalho que aborda a violência sexual contra a mulher, está para além da simples preocupação com criminalização 
dessa prática e a punição do agressor. Entretanto, não se deve concluir que defendamos a impunidade ou que confundamos não punição com a simples impunidade. Todavia, o destaque concedido à vítima é justificado considerando os efeitos que essa forma de violência causa na mesma e da sua necessidade de superação ou de ressignificação do seu sofrimento. Para a justiça restaurativa, o crime não é visto simplesmente como uma violação da norma estatal, mas como um ato que efetivamente causou uma lesão, um dano e, muitas vezes, sofrimento a uma pessoa concreta, tal como ocorre com o estupro.

\section{JUSTIÇA RESTAURATIVA NO DIREITO PENAL BRASILEIRO}

A Justiça Restaurativa está diretamente ligada com a defesa dos Direitos Humanos inseridos nas sociedades, buscando um novo ideal não apenas sancionador, mas especialmente que tenha um alcance de reparação para a vítima. É notório o avanço dos quadros políticos nas principais nações que assimilaram o direito moderno, notadamente no que concerne ao direito penal. No Brasil, a Constituição de 1988 traz o maior rol de proteção dos indivíduos, de modo que esse campo do direito acompanhou aos novos ditames jurídicos, trazendo maior proteção aos acusados.

No entanto, a atuação estatal no controle da criminalidade não tem se mostrado ineficaz, por meio do sistema criminal punitivista, trazendo insatisfação e descrédito social. Desta feita, o sistema criminal punitivista encerra uma certa ausência de legitimidade, seja por não reintegrar o agressor, seja por não prevenir novas práticas delituosas. Demais disso, o referido sistema negligencia por completo o respeito aos interesses da vítima, dado que sua finalidade precípua parece ser a punição do agressor.

No que tange à Justiça Restaurativa, apesar de ser aplicada em diversos países do mundo, é fundamental que exista uma adaptação de seus fundamentos antes de serem aplicados a uma sociedade com características próprias, como a brasileira. O sistema penal brasileiro é classista, ou seja, seleciona sujeitos que devem sofrer a sanção estatal e aqueles que são protegidos pelo Estado. Nesse sentido, a atuação estatal na manutenção da democracia e dos direitos fundamentais é de extrema importância. Contudo, se não é exercido de forma eficaz o Estado deve buscar outros meios para garantir seus objetivos e cumprir com a justiça.

Em primeiro lugar, é necessário mudar a mentalidade social, no sentido do desestímulo da visão estritamente punitivista, de modo a evidenciar os benefícios da Justiça Restaurativa, mesmo entre os atores do mundo jurídico. Atualmente, esse sistema é pouco utilizado em crimes 
graves de natureza sexual, de modo que sua utilização tem sido em relação aos crimes leves, sem violência.

Alguns benefícios são da aplicação do modelo restaurativo: desafogamento do judiciário, com uma grande diminuição do número de processos, e a possibilidade de mudar a visão de que a pena é a única resposta ao crime, fomentando a reparação dos danos, assim como a assunção da responsabilidade consciente por parte do agressor.

A Justiça Restaurativa, não obstante ser uma abordagem centrada na vítima, e, por conseguinte, seu enfoque ser no dano sofrido, tendo em vista a reparação das consequências causadas, não descura da condição do agressor, da mesma forma que envolve a comunidade, como esclarece Zehr (2012, p. 34): “Embora a primeira preocupação deva ser o dano sofrido pela vítima, a expressão 'foco no dano' significa que devemos também nos preocupar com o dano vivenciado pelo ofensor e pela comunidade". Reiteramos, nessa toada, o quanto a abordagem restaurativa coaduna-se à abordagem jurídica dos casos de violência sexual contra as mulheres.

Nos Estados Unidos, existe um programa restaurativo chamado Victims Voices Heard, destinado a casos graves de violência sexual e doméstica após o cumprimento da pena. Após meses de preparação, o referido programa coloca as partes do conflito frente a frente para que possam ser tratadas as violações sofridas.

Programa similar é o Project Restore na Nova Zelândia, o qual também tem enfoque em crimes de violência sexual. Todos os casos são avaliados pelo Restore Clinical Team, o qual é composto por membros qualificados e experientes. Os especialistas realizam reuniões individuas com a vítima, membros de sua família e o agressor para, então, passar para um encontro frente a frente. Tal processo não possui um prazo específico, podendo demorar semanas, meses e até mesmo anos.

\section{CONSIDERAÇÕES FINAIS}

O sistema criminal brasileiro, inclusive seu subsistema e seu sistema prisional, está em crise, em processo de deterioração, de modo que padecem de uma crise de legitimidade por não cumprir suas promessas, seja de prevenção ao crime, seja de reinserção do criminoso à sociedade. Cada vez mais a violência aumenta no país, fato que é demonstrado nos estudos sobre a violência, como o Mapa da Violência, Instituto de Pesquisa Econômico- IPEA, dentre outros. Demais disso, há a morosidade processual que se implantou no judiciário em decorrência do alto 
índice de demandas e dos números escassos de sujeitos que integram o poder judiciário. Nesse sentido, torna-se necessária uma alternativa na resolução de conflitos criminais, buscando um sistema judicial mais humanitário, que traga benefícios não somente para os envolvidos, como para a sociedade.

Os melhores resultados são obtidos quando existe uma abordagem com ação preventiva, educativa e jurídica. Essa perspectiva é muito ausente nas classes mais carentes da sociedade, onde a criminalidade e o desinteresse estatal e social são maiores. Em suma, o sistema jurídico penal de uma sociedade, não pode se desvincular dos elementos sociais dos envolvidos na prática criminosa.

No que concerne à violência do estupro, a Justiça Restaurativa apresenta-se como uma possibilidade de resolução de conflitos, especialmente em razão da primazia conferida à vítima, ao dano sofrido, sem olvidar do agressor. Por ser uma abordagem centrada na vítima, o cerne desse modelo é a restauração do dano e o empoderamento daquela, o que pode contribuir com o processo de resiliência da vítima do estupro. A Justiça Restaurativa mostra-se mais apropriada por apresentar uma resposta tripartida: reparação, responsabilização e reintegração. Assim, embora seja um modelo voltado para os interesses da vítima, não descura do agressor, nem da comunidade. Demais disso, pode ser utilizado - é o que defendemos - como caráter suplementar ao modelo hegemônico, punitivo, para determinados casos nos quais este revele-se inócuo.

Para encerrar ressaltamos que todo esforço em construir instrumentos jurídicos ou mesmo procedimentos interdisciplinares, para a adequada judicialização do estupro será inócua se a atuação judicial continuar a reproduzir os estereótipos de gênero frutos de um senso comum cultural e permanecer refém de modelo criminal punitivista. Tal esforço parece se assemelhar aquele realizado pelas figuras mitológicas das Danaides, cujo trabalho é infindável, todavia sem apresentar qualquer resultado vantajoso, como ocorre com o modelo punitivista. Por isso a aposta no modelo restaurativo para esse tipo de violência.

\section{REFERÊNCIAS}

ACHUTTI, Daniel. Justiça Restaurativa e abolicionismo penal: contribuições para um novo modelo de administração de conflitos no Brasil. 2 ed. São Paulo: Editora Saraiva, 2016.

ANDRADE, Vera, Regina P. Pelas Mãos da Criminologia: O controle penal para além da (des) ilusão. Rio de Janeiro: Revan, 2012. 
ANDRADE, Vera Regina Pereira de. A soberania patriarcal: o sistema de justiça criminal no tratamento da violência sexual contra a mulher. Seqüência: Estudos Jurídicos e Políticos, Florianópolis, v. 26, n. 50, p. 71-102, jan. 2005.. Disponível em: https://periodicos.ufsc.br/index.php/sequencia/article/view/15185. Acesso em: 18 dez. 2019.

BIANCHINI, Edgar Hrycylo. Justiça restaurativa: um desafio à Praxis jurídica. Campinas, SP: Servanda Editora, 2012.

BREVES, Luiza Monteiro. A Aplicação da Justiça Restaurativa nos crimes de violência de gênero e a busca pela superação da cultura punitiva. 2015.65 f. Trabalho de conclusão de Curso (Bacharelado em Direito). Universidade Federal de Santa Catarina, 2015. Disponível em: https://repositorio.ufsc.br/bitstream/handle/123456789/133890/TCC\%20-

\%20Justi\%C3\%A7a\%20Restaurativa\%20e\%20Viol\%C3\%AAncia\%20de\%20G\%C3\%AAnero.p df? sequence $=1>$. Acesso em 13 jan 2019.

BUTLER, Judith. Problemas de gênero: Feminismo e subversão da identidade. Rio de Janeiro: Civilização Brasileira, 2019.

CÂMARA, G. C. Programa de política criminal: orientado para a vítima de crime. São Paulo: Editora Revista dos Tribunais; Coimbra: Coimbra editora, 2008.

CAMPOS, Carmen Hein. A contribuição da criminologia feminista ao movimento de mulheres no Brasil in ANDRADE, Vera Regina (Org.) O verso e o Reverso do controle penal: (Des) aprisionando a sociedade da cultura punitiva,v2. Florianópolis: Fundação Boiteux, 2002.

CAMPOS, Carmen Hein (Org.). Criminologia e Feminismo. Porto Alegre: Editora Sulinas 1999.

CAMPOS, Carmen Hein et al. Cultura do estupro ou cultura antiestupro. Revista Direito GV. São Paulo, vol. 13 n.3, p. 981-1006, Set-Dez 2017.

CONNEL, Raewyn; PEARSE, Rebecca. Gênero: uma perspectiva global compreendendo o gênero- da esfera pessoal á política- no mundo contemporâneo. São Paulo: nVersos, 2015

CUNHA, Rogério Sanches. Manual de Direito Penal: Parte Especial (arts. 121 ao 261). 8 ed. Salvador: JusPODIVM, 2016.

FÓRUM BRASILEIRO DE SEGURANÇA PÚBLICA. Anuário Brasileiro de Segurança Pública. São Paulo: Fórum Brasileiro de Segurança Pública, 2016. Disponível em http://www.forumsegurança.org.br/storange/10_anuario_site_18-11-2016.Acesso em jun.2019

JORGE, Aline Pedra. Em busca da satisfação dos interesses da vítima penal. Rio de Janeiro; Lumen Juris, 2005.

MARQUES, F.M. Justiça restaurativa IN: SANI, A. (coord). Temas de vitimologia: realidades emergentes na vitimação e respostas sociais. Coimbra: Almedina, 2011. 
OLIVEIRA, A. S. Em busca da satisfação dos interesses da vítima penal. Rio de Janeiro: Lumen Juris, 2005.

PARANÁ. Tribunal de Justiça do Estado. $1^{\text {a }}$ Câmara Criminal ACR: 48582 PR Apelação Crime - 0004858-2, Relator: Eli R. de Souza, Data de Julgamento: 12/08/1993.

PERROT, M. Minha história das mulheres. 2ed. São Paulo: Contexto, 2017.

PIMENTEL, Silvia . Gênero e direito IN: PIMENTEL, Silvia (coord.); PEREIRA, Beatriz; MELO, Mônica (Orgs). Direito, Discriminação de gênero e igualdade. Rio de Janeiro: Lumen Juris, 2017.

SAFFIOTI, Heleieth Iara Bongiovani. Gênero patriarcado violência. 2.ed. São Paulo: Expressão popular: Fundação Perseu Abramo, 2015.

SANTOS, Camilla Stefani Saboia dos. Crimes de estupro: a culpabilização da mulher vítima. JUS, 2017. Disponível em: https://jus.com.br/artigos/57810/crimes-de-estupro/1. Acesso em: 14 jun 2018.

VIGARELlO, G. História do estupro: violência sexual nos séculos XVI-XX. Trad. Lucy Magalhães. Rio de Janeiro: Jorge Zahar, 1998.

ZEHR, H. Justiça Restaurativa. Tônia Van Acker (trad.). São Paulo: Palas Athenas, 2012. 